\title{
Development of a gas/liquid phase change actuator for high temperatures
}

\author{
Hiroki Matsuoka ${ }^{1 *}$, Koichi Suzumori $^{2}$ and Takefumi Kanda ${ }^{1}$
}

\begin{abstract}
Gas/liquid phase changes produce large volume changes in working fluids. These volume changes are used as the driving power sources in actuators such as micro-pumps and valves. Most of these actuators are utilized in ordinary temperature environments. However, the temperature range in which the phase change actuator can operate depends on the characteristics of the working fluid. We hypothesized that proper selection of the working fluid and the structure of the actuator can enable such actuators to be applied not only in ordinary environments but also in high temperature environments. Consequently, in this paper, we discuss the design and fabrication of a new gas/ liquid phase change actuator for use in high temperature environments. Our proposed actuator consists of a bellow body, spring, heater, and working fluid. We used the Inconel super alloy, which is highly heat and corrosion resistant, for the bellow and moving parts of the actuator. For the working fluid, we prepared triethylene glycol, which has a boiling point of $287.3^{\circ} \mathrm{C}$ and very low vapor pressure at ordinary temperature. As a result, our proposed actuator can be utilized in high temperature environments up to $300.0^{\circ} \mathrm{C}$. The results of several experiments conducted confirm that our proposed actuator generates $1.67 \mathrm{~mm}$ maximum displacement in a $300.0^{\circ} \mathrm{C}$ atmospheric environment. In addition, we confirmed that the operation of the actuator is stable in that environment. Our results confirm that a gas/liquid phase change actuator can be used in high temperature environments.
\end{abstract}

Keywords: Actuator, Gas/liquid phase change, High temperature, Triethylene glycol, Bellow

\section{Background}

Phase changes in materials, resulting from temperature changes, produce huge volume changes, especially in liquid/gas phase changes. This attribute is utilized to provide a power source for micro-pumps and valves in combination with MEMS (micro-electromechanical system) heaters, micro-channels, diaphragms, and membranes [1-10]. Kato et al. used this phenomenon to provide a power source for actuators and robots. They made a metal bellow actuator to control cutting equipment and a pipe inspection robot [11,12]. Phase change is used not only in actuators but also in some kinds of pressure sources. For example, Kitagawa et al. used the triple point of carbon dioxide as a mobile pressure source

\footnotetext{
*Correspondence: matsuoka9@act.sys.okayama-u.ac.jp

1 Okayama University, 3-1-1, Tsushima-naka, Kita-ku, Okayama 700-8530, Japan

Full list of author information is available at the end of the article
}

[13], and Shibuya et al. developed a buoyancy control device for underwater robots using paraffin oil [14].

The actuators described above were developed for use in ordinary environments. In contrast, our aim is to utilize these phase change actuators in special environments. In particular, driving actuators in high temperature environments is a typical example of the special environments being considered. For example, in the hydrothermal synthesis method, which is one of the methods used to fabricate piezoelectric devices, the water solution inside the high temperature chamber needs to be agitated [15]. In one instance where this process was used, the water solution was agitated using an autoclave-an end-overend shaker with heat. Fabrication of the $(\mathrm{Pb}, \mathrm{La})(\mathrm{Zr}, \mathrm{Ti})$ $\mathrm{O}_{3}$ (PLZT) film took $24 \mathrm{~h}$. Not only the rotation condition but also the attitude of the sample will affect the quality of the fabrication. The actuators, which produce the inclination of the shaker, are predictably effective devices. Another example is the fabrication process for the ferric oxide crystal via the floating-zone melting method [16].

\section{Springer}

(c) 2016 Matsuoka et al. This article is distributed under the terms of the Creative Commons Attribution 4.0 International License (http://creativecommons.org/licenses/by/4.0/), which permits unrestricted use, distribution, and reproduction in any medium, provided you give appropriate credit to the original author(s) and the source, provide a link to the Creative Commons license, and indicate if changes were made. 
In this process, the partially melted sample is turned and pulled inside the chamber for growth. Both the processes require $8-24 \mathrm{~h}$ and a single directional drive in order to fabricate the tiny sample. We believe that an actuator that can realize linear motion in high temperature environments can rectify these quality problems.

In previous work, we targeted these environments for utilization of actuators and proposed gas/liquid phase change actuators. We subsequently fabricated an actuator driven by the gas/liquid phase change of water. This actuator consisted of a cylinder as a vessel and actuation device, an external heater to excite the phase change, and a spring that controlled the speed of motion. Our proposed actuator was driven in a $180{ }^{\circ} \mathrm{C}$ environment. Thus, we realized directional motion with gas/liquid phase changes in a high temperature environment using that actuator $[17,18]$.

In this paper, we discuss the development of another actuator for utilization in high temperature environments. Our proposed actuator is composed of an Inconel alloy bellow (which is highly heat and corrosion resistant), a spring, a heater with built-in temperature sensor, and working fluid. The bellow produces direct motion without friction when it is moving. This friction is significant in cylinder type actuators; it can cause leaking of the working fluid and disturb the motion of the actuator. Although it has the same bellow shape, our proposed actuator can be sealed very easily and has a more simplified structure.

Springs change the speed of an actuator; when a hard spring is attached, the actuator is driven at a slow speed. Conversely, a soft spring produces a high speed for the actuator. These characteristics were confirmed in our previous study.

In this paper, we explain how we chose the new working fluid to facilitate operation of the actuator in high temperature environments. The triethylene glycol (TEG) working fluid has a liquid phase and a boiling point of $287.3{ }^{\circ} \mathrm{C}$ under ordinary atmospheric pressure conditions [19]. These characteristics enable our proposed actuator to operate in a $300.0{ }^{\circ} \mathrm{C}$ environment.

In experiments conducted, in which the actuator was driven in a $300.0{ }^{\circ} \mathrm{C}$ atmospheric temperature environment by a heater assembled in the actuator, a maximum displacement of $1.67 \mathrm{~mm}$ with $2700 \mathrm{~J}$ of input power was produced. The results confirmed that our new gas/liquid phase change actuator can be driven in $300.0^{\circ} \mathrm{C}$ high temperature environments with TEG working fluid.

\section{Basic principle underlying the gas/liquid phase change actuator}

Our proposed actuator is driven by the gas/liquid phase change of its working fluid. When the working fluid is heated, its vapor pressure increases and pushes out the chamber.

The fundamental structure of the proposed actuator is shown in Fig. 1. The actuator consists of a variable volume chamber, springs that produce the reactive force against vapor pressure, heating device, and working fluid.

A bellow is a variable volume vessel. In previous work, we used a cylinder, but this structure has a sliding member in its body. As a result, there was much friction when it was being driven and the working fluid also leaked. Considering the application of our actuator to high temperature environments, we surmised that these issues would be a bottleneck. Consequently, we designed the bellow to be driven without friction because the expansion and contraction characteristics of a bellow are produced by its distinctive structure. In addition, the chamber also includes the spring properties itself.

The springs produce a refractive force against the vapor pressure, in order to control the temperature sensitivities of the actuator. The fundamental theoretical characteristics can be calculated using the very simple equation

$$
k\left(x_{0}+x\right)=A \cdot P_{\text {bellow }}
$$

where $k$ is the spring constant of the actuator; $x_{0}$ and $x$ are the initial and produced displacements, respectively; $A$ is the pressurized area of the bellow; and $P_{\text {bellow }}$ is the inner pressure of the bellow, which is the vapor pressure of the working fluid.

The general properties underlying the concept of the actuator are illustrated in Fig. 2. When a stiff spring is attached to the actuator, the actuator generates a small displacement with respect to the temperature increment. Conversely, when a soft spring is attached, the actuator generates a large displacement with respect to the temperature increment.

The characteristics of the actuator also depend on the properties of the working fluid. The inherent vapor

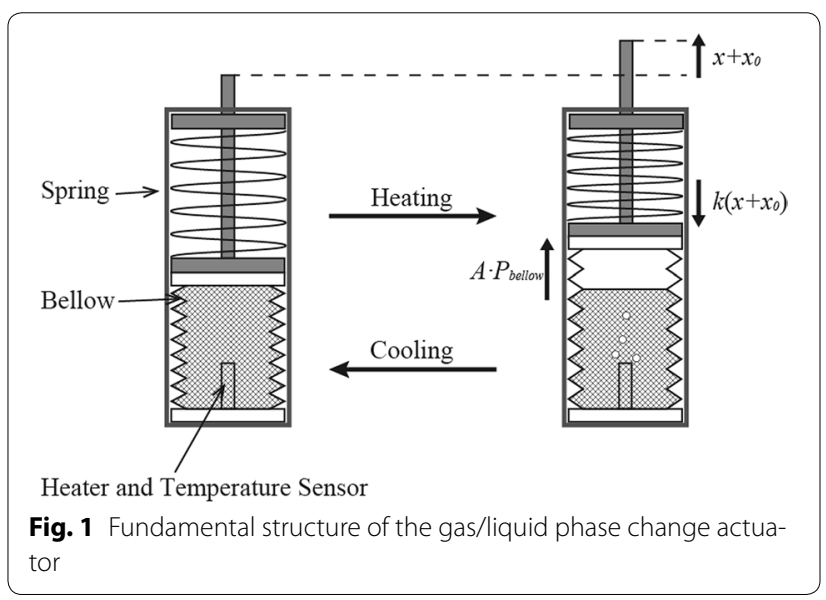




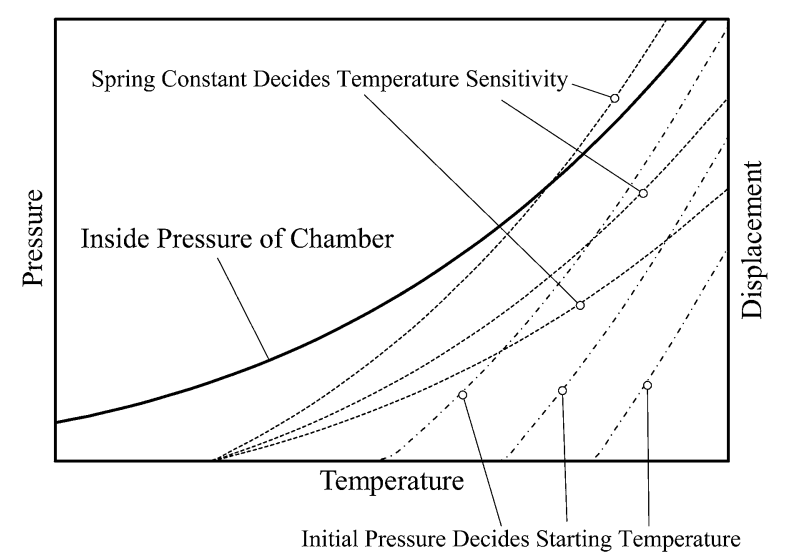

Fig. 2 Basic underlying concepts of the gas/liquid phase change actuator

pressure curve of the working fluid determines the driving temperature range of the actuator. Thus, by selecting an appropriate working fluid, we can set the operating temperature range of the actuator.

Various kinds of modes of heating exist; for example, fire, electrical heating, chemical reaction, induction heating, Peltier heating, and IR light.

In our previous work, we confirmed the adequacy of these fundamental characteristics of gas/liquid phase change actuators and designed an actuator that could be driven by the phase change of water in a $180.0{ }^{\circ} \mathrm{C}$ environment.

\section{Design of the actuator}

We designed a prototype actuator based on our proposed driving principle. As shown in Fig. 3, our actuator consisted of bellows, spring, chassis, and heater unit-which includes the temperature sensor.

The bellow, the most important part of the actuator, was fabricated using Inconel 600 super alloy-an austenite Nickel-Chromium based alloy. The target temperature, $300.0{ }^{\circ} \mathrm{C}$, is the temperature used for low

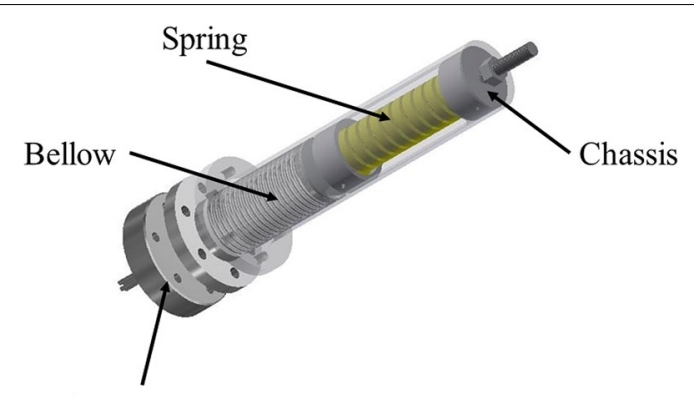

Heater and Temperature Sensor

Fig. 3 Design of the actuator temperature annealing of stainless steel. This heat treatment process causes stainless steel to lose its corrosion resistance and its mechanical properties to change. By contrast, Inconel alloy has better corrosion and heat resistance than stainless steel as a result of its stable passivating oxide layer. Hence, we chose Inconel super alloy for the actuator. This bellow had outer diameter $22.0 \mathrm{~mm}$, inner diameter $15.2 \mathrm{~mm}$, and length $65.0 \mathrm{~mm}$-with a welded $40 \mathrm{~mm}$ diameter flange and a tiny cap, $0.12 \mathrm{~mm}$ double layer thickness wall, 19 replications, and a $13.5 \mathrm{~N} /$ $\mathrm{mm}$ spring constant. The working fluid was poured into this chamber.

The compression coil spring was set on the top of the bellow. This spring was made from oil tempered $\mathrm{SiCr}$-alloyed valve spring wire (SWOSC-V). When the actuator is driven, the bellow extends, and the spring is compressed. Consequently, the spring constant of the actuator is calculated by summing those of the bellow and the spring.

Incidentally, the spring constants are also temperature dependent. In general, the spring constant of a coil spring is calculated using the equation

$$
\mathrm{k}_{\text {spring }}=\frac{G d^{4}}{8 N_{a} D^{3}}
$$

where $k_{\text {spring }}$ is the spring constant, $G$ is the modulus of rigidity, $d$ is the diameter of the wire, $N_{a}$ is the number of turns, and $D$ is the average diameter of the coil. This equation reflects the fact that the spring constant of the coil spring depends on the modulus of rigidity of the metal. The modulus of rigidity of SWOSC-V can be calculated using the regression formula [20]:

$$
\mathrm{G}=7308+\left(-2.604 \times 10^{7}\right) \exp \left(\frac{-6800}{T+273}\right)
$$

where $T$ is temperature. Meanwhile, approximate equations for the spring constants of metal bellows $k_{\text {bellow }}$ are given by [21]

$$
\begin{aligned}
\mathrm{k}_{\text {bellow }} & =\frac{2 \pi m^{2} E t^{3}}{3 n\left(m^{2}-1\right) b^{2}} /\left\{c^{2}-1-\frac{4 c^{2}}{c^{2}-1}(\log c)^{2}\right\} \\
m & =\frac{1}{v} \\
c & =\frac{a}{b}
\end{aligned}
$$

where $E$ is the modulus of longitudinal elasticity (Young's modulus), $n$ is the number of replications, $a$ and $b$ are the radius of the outer and inner diameter, respectively, $t$ is the thickness of the bellow's wall, and $v$ is Poisson's ratio. From these equations we can estimate the temperature 
dependence of the spring constant of the actuator. The spring constant of actuator $k_{\text {actuator }}$ can be calculated using the following equation:

$$
k_{\text {actuator }}=k_{\text {spring }}+k_{\text {bellow }}
$$

The results of calculations with the spring constant of the coil spring at $13.9 \mathrm{~N} / \mathrm{mm}$ and of the bellow at $13.5 \mathrm{~N} \mathrm{~mm}$ under ordinary temperature are shown in Fig. 4. From these results, we determined that at $300.0^{\circ} \mathrm{C}$ atmospheric temperature, the spring constant of the actuator declined by $5 \%$.

The static displacement of the actuator is affected not only by vapor pressure but also by thermal expansion of the working fluid. Thus, the theoretical static displacement of actuator $x$ was calculated using the equation

$$
x=\varepsilon L_{0}\left(T-T_{0}\right)+\frac{A \cdot P_{\text {workingfluid }}}{k_{\text {actuator }}}
$$

where $\varepsilon$ is the thermal expansion ratio of the working fluid, $L_{0}$ is the initial length of the bellow under ordinary temperature, $T_{0}$ and $T$ are the ordinary temperature and the current temperature, respectively, and $P_{\text {working fluid }}$ is the vapor pressure of the working fluid.

As shown in Fig. 5, the heater is welded onto the flange. It has a rated output of $24 \mathrm{~V}$ at $15 \mathrm{~W}$, and a K-type thermoelectric couple on the top of the heating rod, which is $8 \mathrm{~mm}$ in diameter and $24 \mathrm{~mm}$ in length. All of these parts were inserted into the chassis and the actuator finally assembled, as shown in Fig. 6 . The actuator has a length of $220 \mathrm{~mm}$, flange diameter $40 \mathrm{~mm}$, and outer diameter $25 \mathrm{~mm}$. The displacement produced can be observed from the slit in the middle of the chassis or the output shaft at the top of the actuator.

We chose TEG, which has melting point $-14.3^{\circ} \mathrm{C}$ and boiling point $287.3^{\circ} \mathrm{C}$ at ordinary pressure, as the working fluid. This liquid is clear and colorless and has the chemical formula $\mathrm{C}_{6} \mathrm{H}_{14} \mathrm{O}_{4}$. This working fluid has a very small vapor pressure at ordinary temperature [22]. This

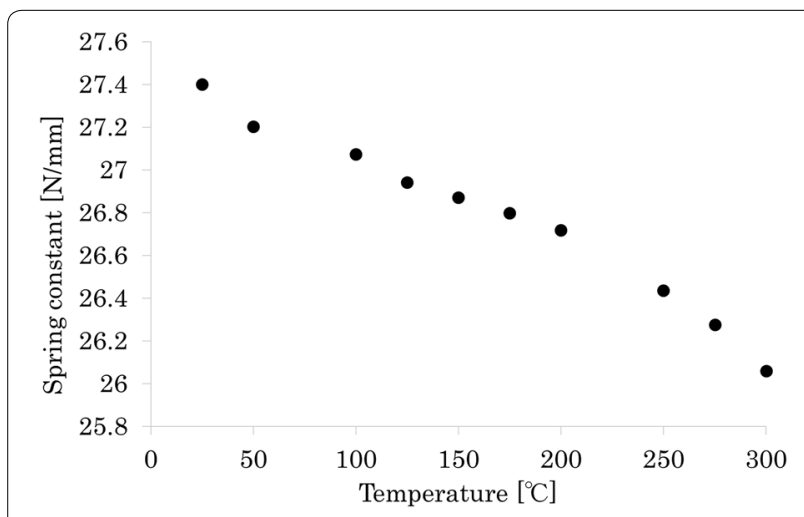

Fig. 4 Temperature dependence of the spring constant

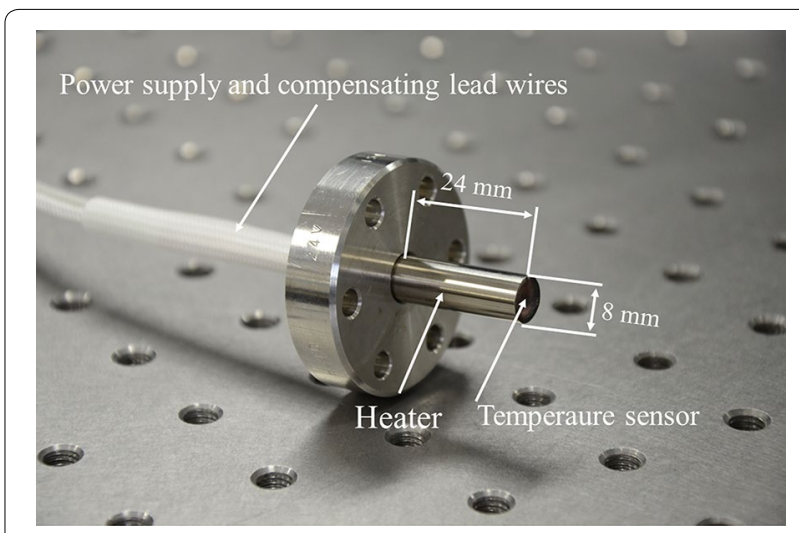

Fig. 5 Flanged heater

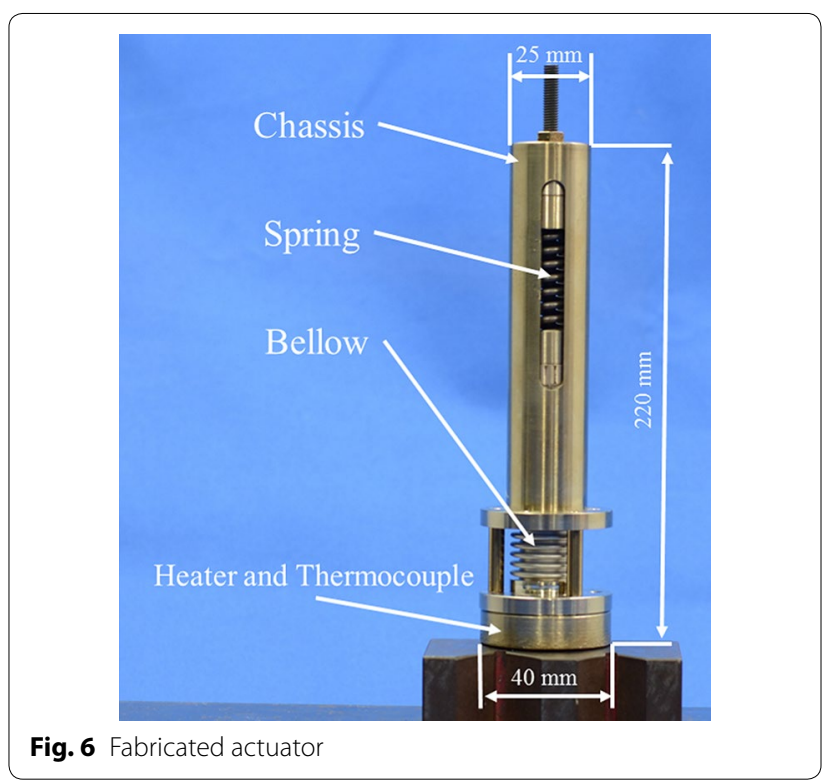

is because we chose a liquid that is suitable as a working fluid for driving the actuator in a $300.0{ }^{\circ} \mathrm{C}$ environment. The basic specifications of TEG are shown in Table 1.

\section{Experiments and properties of the actuator}

\section{Static properties of the actuator}

We conducted an experiment to evaluate the basic static properties of our prototype actuator. In this experiment, we determined the relationship between the atmospheric temperature and the displacement of the actuator, which is produced by atmospheric temperature. The temperature was controlled via a constant temperature reservoir and the displacement measured at 25.0, 100.0, 200.0, 275.0 , and $300.0{ }^{\circ} \mathrm{C}$, respectively. Prior to each measurement, the actuator was placed in the respective temperature environment for $1 \mathrm{~h}$. This was carried out to enable the temperature of the actuator to accord with that of the constant temperature reservoir. The displacement was 
Table 1 Basic characteristics of TEG

\begin{tabular}{ll}
\hline Chemical formula & $\mathrm{C}_{6} \mathrm{H}_{14} \mathrm{O}_{4}$ \\
Melting/boiling point & $-14.3^{\circ} \mathrm{C} / 287.3^{\circ} \mathrm{C}$ \\
Specific gravity & 1.1255 \\
Coefficient of expansion & 0.00072 \\
\hline
\end{tabular}

measured by image processing using a photograph taken from the outside of the constant temperature reservoir through the observation window. The experimental setup is shown in Fig. 7.

In this experiment, $15.9 \mathrm{~g}$ of degassed TEG was poured into the bellow and the actuator sealed while ensuring that no air was included. TEG has a thermal expansion ratio of $7.2 \times 10^{-4} /{ }^{\circ} \mathrm{C}$ at $55.0{ }^{\circ} \mathrm{C}$ [23]. Thus, an increase in temperature from room temperature to $300.0{ }^{\circ} \mathrm{C}$ results in a $22 \%$ increase in the volume of TEG.

The SWOSC-V spring, with a spring constant of $13.9 \mathrm{~N} / \mathrm{mm}$, was inserted into the chassis. As discussed previously, the spring constant of an actuator has a small temperature dependence. In this case, a temperature increase from 25.0 to $300.0{ }^{\circ} \mathrm{C}$ resulted in a decrease in the spring constant from 27.4 to $26.1 \mathrm{~N} / \mathrm{mm}$.

The experimental results obtained are shown along with the theoretical displacement in Fig. 8. The actuator was displaced $13.1 \mathrm{~mm}$ at $300.0^{\circ} \mathrm{C}$ as a result of the thermal expansion and vapor pressure of TEG. As shown in Fig. 8, the theoretical displacement calculated using Eq. (8) is consistent with the actual experimental value. The output force of the actuator that regards a spring as a load and the vapor pressure of TEG are shown in Figs. 9 and 10 . The results show that the experimental values are identical to theoretical values.

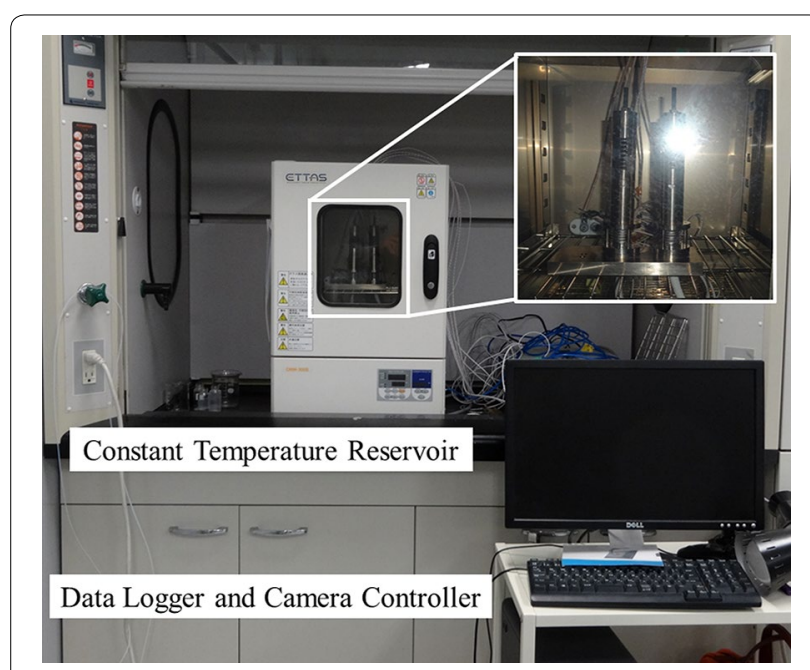

Fig. 7 Experimental setup
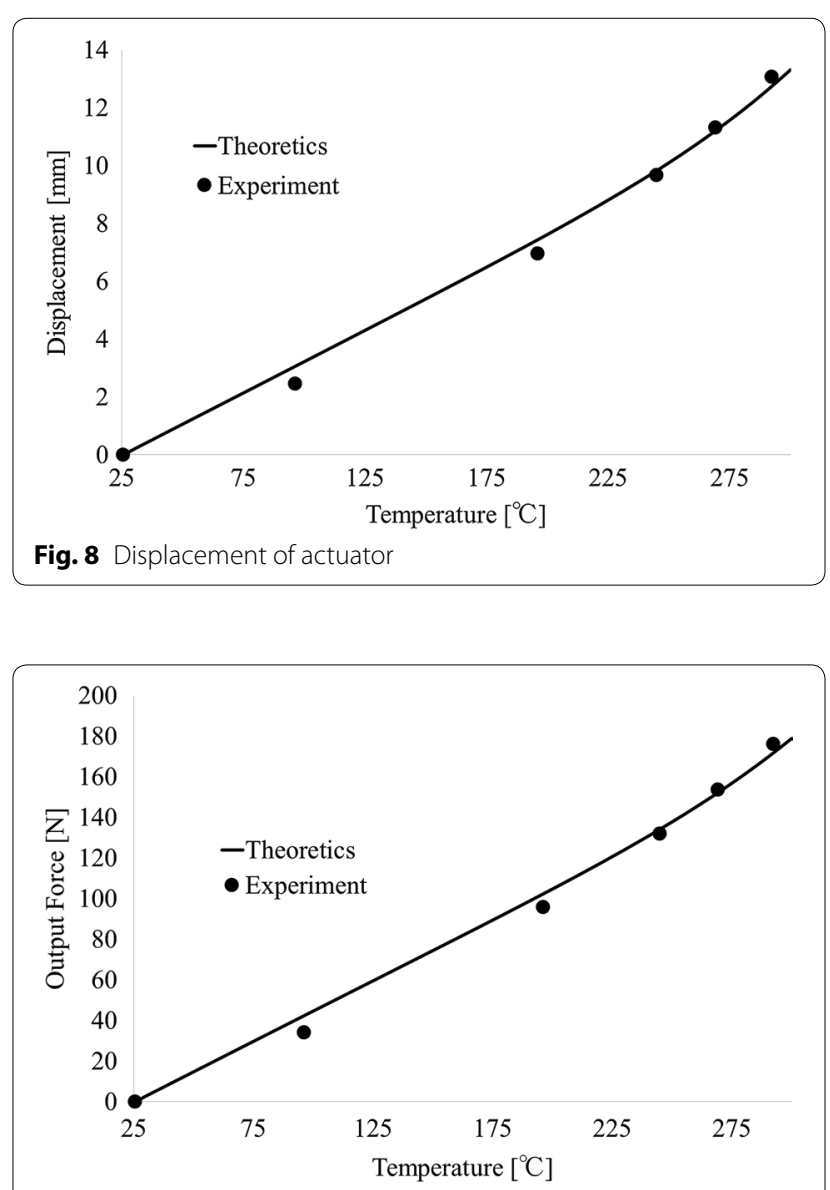

Fig. 9 Output force of actuator

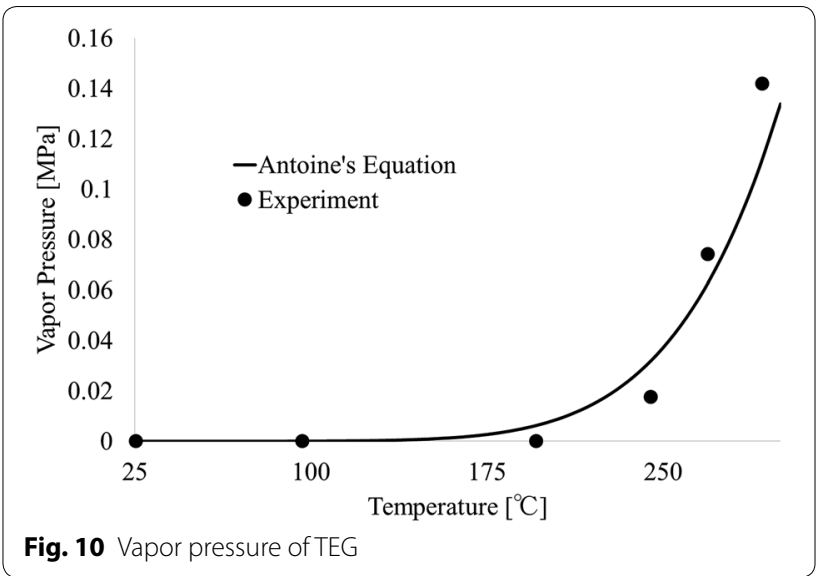

\section{Dynamic properties of the actuator}

We also evaluated the dynamic properties of the proposed actuator in order to verify that it can be utilized in a high temperature environment. In the experiment conducted, the atmospheric temperatures were set via a constant temperature reservoir to $25.0,100.0,200.0,250.0,275.0$, and 
$300.0{ }^{\circ} \mathrm{C}$, respectively. After leaving the actuator at each respective temperature for $30 \mathrm{~min}, 24 \mathrm{VDC}$ was applied to the heater, which resulted in the working fluid being heated in $180 \mathrm{~s}$. After being heated, the actuator was then cooled by heat radiation. The current applied to the heater was $0.6 \mathrm{~A}$, and the applied energy was $2700 \mathrm{~J}$. The experimental results obtained are shown in Fig. 11. In the experiment, the actuator produced $1.67 \mathrm{~mm}$ maximum displacement in the $300.0{ }^{\circ} \mathrm{C}$ environment with a $56.2^{\circ} \mathrm{C}$ temperature increment. Further, in all the environments, the actuator ceased moving immediately as the heating stopped. In addition, the actuator did not revert to any of its initial states. In the initial states, the temperature sensor inside of the bellow indicated 25.5, 96.3, 196.1, 244.9, 269.1, and $292.3{ }^{\circ} \mathrm{C}$, respectively. However, the K-type thermocouple has a $5 \%$ measuring error.

We also applied the same energy five times in the $300.0{ }^{\circ} \mathrm{C}$ environment. The results are shown in Fig. 12 . After the first heating, the actuator did not return to its initial state within $3000 \mathrm{~s}$. We assumed that this phenomenon was because the initial temperature of the

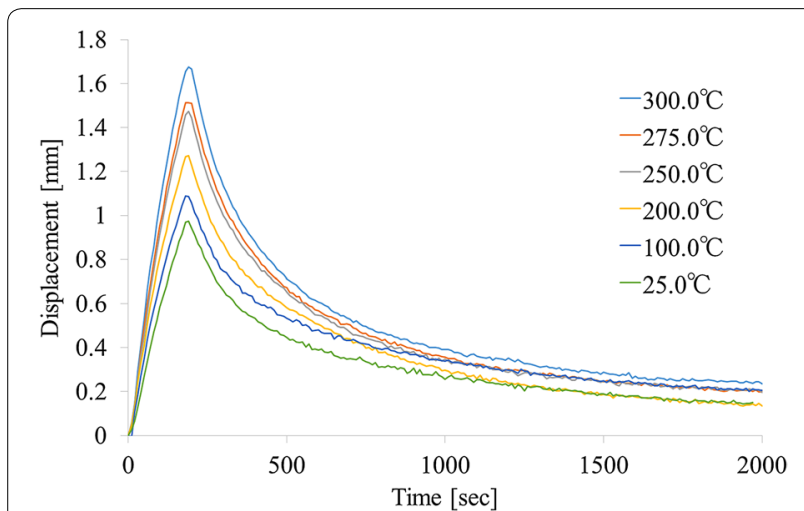

Fig. 11 Dynamic characteristics of the actuator at various temperatures

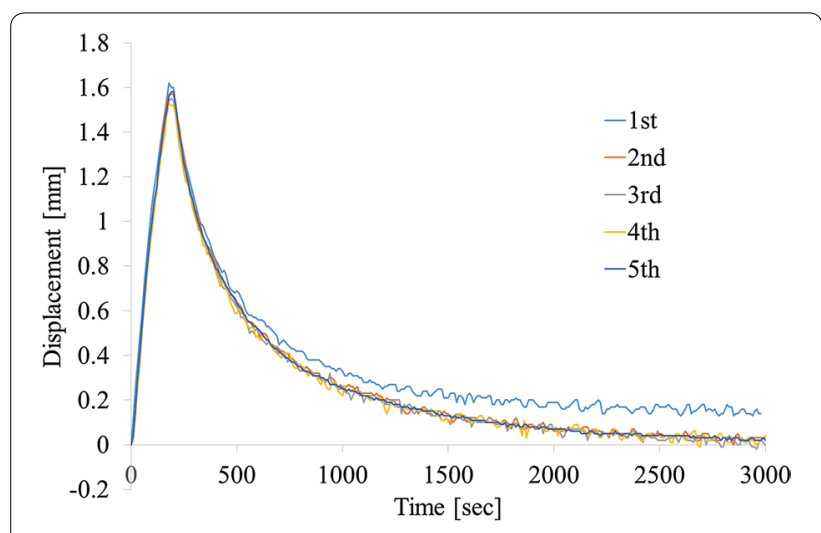

Fig. 12 Dynamic characteristics of the actuator at $300.0^{\circ} \mathrm{C}$ working fluid was lower than the atmospheric temperature. However, the other four experiments generated exactly the same displacements. In these experiments, the actuator took $40.8 \mathrm{~N}$ average force with $2700 \mathrm{~J}$ of input energy in $180 \mathrm{~s}$. The results of these experiments confirm that our proposed actuator can produce stable movements in a $300.0{ }^{\circ} \mathrm{C}$ high temperature environment.

\section{Conclusions}

We proposed a new actuator that is driven by the gas/ liquid phase of a working fluid for high temperature environments. Phase change actuators are driven by the heating of working fluids; thus, their characteristics depend on the characteristics of the working fluid and the springs that produce the reactive force against the vapor pressure.

We designed and fabricated an actuator that can be utilized in a $300.0{ }^{\circ} \mathrm{C}$ high temperature environment. The actuator consists of a bellow body, spring, heater with a built-in temperature sensor, and TEG working fluid. The bellow was fabricated from Inconel super alloy, which is highly heat and corrosion resistant, and can generate displacements without friction. The TEG working fluid has a very low vapor pressure at ordinary temperature and a boiling point of $287.3{ }^{\circ} \mathrm{C}$. Consequently, the proposed actuator is controllable in $300.0{ }^{\circ} \mathrm{C}$ temperature environments.

The results of static evaluation of the characteristics confirmed that the theoretical properties are consistent with the experimental results. The actuator is heated by atmospheric temperature and produces a displacement using both vapor pressure and thermal expansion of the working fluid.

We operated this actuator using a heater assembled in the actuator in several temperature environments. The results showed that the actuator can be driven in all the environments tested. In the $300.0{ }^{\circ} \mathrm{C}$ environment, the actuator generated $1.67 \mathrm{~mm}$ maximum displacement using $2700 \mathrm{~J}$ of input power. In addition, we operated the actuator fitfully five times in a $300.0{ }^{\circ} \mathrm{C}$ environment in exactly the same condition. The results of this examination confirmed that the actuator is stably driven.

Thus, our proposed gas/liquid phase change actuator is suitable for operation in $300.0^{\circ} \mathrm{C}$ environments. In order to put this actuator to practical use, the operating time needs to be reduced and a controlling system added. We believe that this actuator can be driven in even higher temperature environments in the future.

\section{Authors' contributions}

HM carried out design, experiment, evaluating of the actuator and drafted the manuscript. KS and TK conceived of the study, and participated in its design and coordination and helped to draft the manuscript. All authors read and approved the final manuscript. 


\section{Authors' information}

HM was born in July 3, 1986. He received his B. Eng. and M. Eng. from Okayama University, Japan in 2010 and 2012, respectively. He has been a doctoral student at the graduate school of Okayama University since 2012. His current research interest is in the area of actuators for special environments.

KS was born in 1959. He received a Doctor's Degree from Yokohama National University in 1990. He worked for the Toshiba R\&D Center from 1984 to 2001 and for the Micromachine Center, Tokyo, from 1999 to 2001. He was a professor at Okayama University, Japan since 2001-2014. He has been a professor a Tokyo Institute of Technology, Japan since 2014. He is a member of the Japan Society of Mechanical Engineers, the Robotics Society of Japan, IEEE and the Institute of Electrical Engineers of Japan.

TK was born in Fukuoka, Japan, on June 18, 1972. He received his B. Eng., M. Eng., and Dr. Eng. in precision machinery engineering from the University of Tokyo, Japan in 1997, 1999, and 2002, respectively. From 2002 to 2007, he was a research associate and lecturer at Okayama University, Japan. Since 2007, he has been an associate professor at Okayama University. His research interests are micro sensors, micro actuators, micro systems, and piezoelectric film. He is a member of the Japan Society for Precision Engineering, the Institute of Electrical Engineers of Japan, IEEE, the Japan Society of Mechanical Engineers, and the Robotics Society of Japan.

\section{Author details}

${ }^{1}$ Okayama University, 3-1-1, Tsushima-naka, Kita-ku, Okayama 700-8530, Japan. ${ }^{2}$ Tokyo Institute of Technology, 2-12-1-11-60, Ookayama, Meguro-ku, Tokyo 152-8550, Japan.

\section{Acknowledgements}

We sincerely appreciate the help received from Dr. Y. Sakata and Mr. Y. Yamada through valuable discussions held. This study was partly supported by the Fluid Power Technology Promotion Foundation.

\section{Competing interests}

The authors declare that they have no competing interests.

Received: 19 May 2015 Accepted: 7 January 2016

Published online: 16 January 2016

\section{References}

1. Henning AK (1998) Liquid and gas-liquid phase behavior in thermopneumatically actuated microvalves. In: SPIE3515, Micro Fluidic Devices and Systems, pp. 53-63, Sante Clara, CA

2. Takao H, Miyamura K, Ebi H, Ashiki M, Sawada K, Ishida M (2005) A MEMS microvalve with PDMS diaphragm and two-chamber configuration of thermo-pneumatic actuator for integrated blood test system on silicon. Sens Actuators A 119(2):468-475

3. Henning AK (2006) Comprehensive model for thermopneumatic actuators and microvalves. J Microelectromech Syst 15(5):1308-1318

4. Bardaweel HK, Anderson MJ, Weiss LW, Richards RF, Richards CD (2009) Characterization and modeling of the dynamic behavior of a liquidvapor phase change actuator. Sens Actuators A 149(2):284-291

5. Song GE, Kim KH, Lee YP (2007) Simulation and experiments for a phase-change actuator with bistable membrane. Sens Actuators A 136(2):665-672
6. Ogden S, Jonsson J, Thornell G, Hjort K (2012) A latchable high-pressure thermohydraulic valve actuator. Sens Actuators A 188:292-297

7. Bardaweel HK, Bardaweel SK (2013) Dynamic simulation of thermopneumatic micropumps for biomedical applications. Microsyst Technol 19(12):2017-2024

8. Lee H, Richards CD, Richards RF (2013) Experimental and numerical study of microchannel heater/evaporators for thermal phase-change actuators. Sens Actuators A 195:7-20

9. Kong LX, Parate K, Abi-Samra K, Madou M (2015) Multifunctional wax valves for liquid handling and incubation on a microfluidic CD. Microfluid Nanofluid 18(5-6):1031-1037. doi:10.1007/s10404-014-1492-x

10. Lei KF, Chen KH, Chang YC (2014) Protein binding reaction enhanced by bi-directional flow driven by on-chip thermopneumatic actuator. Biomed Microdevices 16(2):325-332

11. Ono M, Izumi T, Kato S (2005) Proposal of a gas-liquid phase-change microactuator and its applications. In: Proceedings of the ASPE 2005 annual meeting, Norfolk, 2005, pp 138-141

12. Ono M, Kato $S$ (2010) A study of an earthworm type inspection robot movable in long pipes. Int J Adv Rob Syst 7(1):85-90

13. Wu H, Kitagawa A, Tsukagoshi H (2005) Development of a portable pneumatic power source using phase transition at the triple point. In: Proceedings of the JFPS international symposium on fluid power, Tsukuba, 2005

14. Inoue T, Shibuya K, Nagano A (2010) Underwater robot with a buoyancy control system based on the spermaceti oil hypothesis development of the depth control system. In: Proceedings of 2010 IEEE/RSJ international conference on intelligent robots and systems (IROS) 2010, Taipei, 2010

15. Yamaguchi D, Tonokai A, Kanda T, Suzumori K (2013) Light-driven actuator using hydrothermally deposited PLZT film. IEEJ Trans Sensors Micromach 133(8):330-336

16. Ikeda N, Ohsumi H, Ohwada K, Ishii K, Inami T, Kakurai K, Murakami Y, Yoshii K, Mori S, Horibe Y, Kitô H (2005) Ferroelectricity from iron valence ordering in the charge-frustrated system $\mathrm{LuFe}_{2} \mathrm{O}_{4}$. Nature 436(7054):1136-1138

17. Suzumori K, Matsuoka H, Wakimoto S (2012) Novel actuator driven with phase transition of working fluid for uses in wide temperature range. In: Proceedings of 2012 IEEE/RSJ international conference on intelligent robots and systems, Algarve, 2012

18. Matsuoka H, Suzumori K (2014) Gas/liquid phase change actuator for use in extreme temperature environments. J Ref Int J Autom Technol 8(2):140-146

19. Stull DR (1947) Vapor pressure of pure substances. Organic and inorganic compounds. Ind Eng Chem 39(4):517-540

20. Committee for High Temperature Springs (1989) Long-term elevated temperature setting properties of oil tempered $\mathrm{Cr}$-Si steel wire (SWOSCV) and stainless steel wire (SUS304-WPB) springs. Trans Jpn Soc Spring Eng 1989(34):59-84 (in Japanese)

21. Takenaka T (1959) On the effective area and stiffness of bellous. Trans Jpn Soc Mech Eng 25(149):43-46 (in Japanese)

22. NIST WebBook (2015) National Institute of Standards and Technology, http://webbook.nist.gov/cgi/cbook.cgi?!D=C112276\&Units=SI\&Mask=4 \#Thermo-Phase. Accessed 14 Jan 2016

23. Akram MS, Haider B, Afzal W (2010) Thermophysical behavior of some industrially important associating fluids: thermal expansion coefficients. Paper presented at the 3rd Symposium on Engineering Science, Lahore, Pakistan 